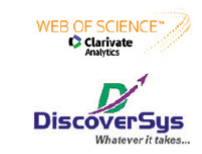

Published by DiscoverSys

\section{The correlation of 25-Hydroxyvitamin D (25-(OH)D) to IgE level, eosinophil, and Asthma Control Test (ACT) score in asthma patients}

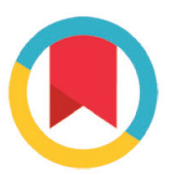

CrossMark

\author{
Ery Olivianto ${ }^{1}$, Ade Habibi ${ }^{1 *}$, Muchammad Fahrul Udin' ${ }^{1}$, HMS Chandra Kusuma ${ }^{1}$
}

\section{ABSTRACT}

Background: Asthma is a heterogenouse disease with chronic inflammation which is characterized by hyperreactivity and obstruction of respiratory tract. Many hypothesis of asthma were related with nutrition, such as vitamin D status. Vitamin $D$ is a precursor of steroid hormone that has immunomodulator effect but the relationship of asthma and vitamin D still controversial. This study aims to find the relationship of vitamin $D(25-(\mathrm{OH}) \mathrm{D})$ with level of $\lg \mathrm{E}$, Eosinophils, and asthma control test (ACT) in mild to moderate pediatric asthmatic patient.

Method: An observational analytic study with cross-sectional approach has been conducted among 40 pediatric asthmatic patients by consecutive sampling technique. Data regarding gender, age, vitamin D status, the levels of 25-(OH)D, lgE, Eosinophil, and
ACT score were assessed in this study. Correlation analysis test was used as statistical analysis using SPSS version 20 for Windows. Result: Most of respondents were male (70.0\%), 5-7 years of age range (52.5\%), and insufficient of vitamin D (20-30 ng/ml) (45.0\%). The recent study suggests a significant negative relationship between serum $25(\mathrm{OH}) \mathrm{D}$ levels with total immunolobulin E levels $(p=0.002 ; r=-0.476)$ and eosinophils $(p=0.002 ; r=-0.479)$. However, the $25-(\mathrm{OH}) \mathrm{D}$ level did not show a significant relationship with the ACT score $(p=0.195 ; r=0.209)$.

Conclusion: Negative relationship was found between total serum $25(\mathrm{OH}) \mathrm{D}$, total immunoglobulin $\mathrm{E}$, and eosinophils in children with asthma. Moreover, $25(\mathrm{OH}) \mathrm{D}$ was not related to ACT score in children with asthma.
'Department of Child Health, Medical Faculty, Universitas Brawijaya, Malang, Indonesia

*Corresponding to: Ade Habibi; Department of Child Health, Medical Faculty, Universitas Brawijaya, Malang, Indonesia;

dr.adehabibi@gmail.com
Received: 2020-02-23 Accepted: 2020-04-02 Published: 2020-05-07

Keywords: Asthma, Vitamin D, Immunoglobulin E, ACT Score

Cite this Article: Olivianto, E., Habibi, A., Udin, M.F., Kusuma, H.M.S.C .2020. The correlation of 25-Hydroxyvitamin D (25-(OH)D) to lgE level, eosinophil, and Asthma Control Test (ACT) score in asthma patients. Pediatrics Sciences Journal 1(1): 1-5.

\section{INTRODUCTION}

Asthma is a chronic airway inflammation which is associated with hyperresponsiveness and airway obstruction. Moreover, asthma is causing obstruction symptoms like wheezing, shortness of breath, and heavily in-breath. ${ }^{1}$ The frequent prevalence of asthma found in child age; consequently, asthma is the leading morbidity causes in children throughout the world. ${ }^{2}$ In 2013 the prevalence of asthma in Indonesia was $4.5 \%$. $^{3}$

The mechanism of asthma is not very clear because the asthma manifestations are different for each individual. Interleukin IL-4, IL-5, and IL-13 (cytokine type $\mathrm{T}$ helper type 2) play a role in the pathogenesis of asthma which is associated with increasing the eosinophils and the immunoglobulin $\mathrm{E}$ (Ig E). Thus, the Immunoglobulin $\mathrm{E}$ will be activating mast cells which are causing mast cell degranulation, hence releasing inflammation mediators such as histamine, prostaglandin, and leukotriene. These mediators will aggravate asthma symptoms by contracted the bronchial smooth muscle, increasing mucous secretion, and vasodilation. ${ }^{4}$ Besides, increasing of Immunoglobulin E, asthma patients also increase in the number of eosinophils after specific allergens. Eosinophils release various cytotoxic products and produce various cytokines that can cause epithelial damage, oedema, excessive mucus production and bronchial hyperreactivity. ${ }^{5}$

Vitamin D is a precursor of steroid hormones that have an immunomodulatory effect. Hence, it also plays a role in regulating, differentiating, and producing the cytokine. ${ }^{6-8}$ The relationship of vitamin $\mathrm{D}$ with asthma is still controversial. Recent studies said that vitamin $\mathrm{D}$ has no relationship and not affected to asthma. ${ }^{9-11}$ Oppositely, Hypponen's research states that vitamin $\mathrm{D}$ levels has positive relationship with immunoglobulin $\mathrm{E}$ in patients with asthma. ${ }^{11}$ Because of these different results, this study aims to determine the correlation of 
vitamin D (25 (OH) D) levels with immunological profiles in the form of IgE and eosinophil levels and examine the relationship with clinical aspects of ACT scores in mild and moderate asthma children.

\section{METHOD}

This study used a cross-sectional observation design, conducted in 2019 at the Children's Hospital Dr Saiful Anwar Malang. Subjects were diagnosed with asthma based on the national asthma guidelines criteria and were undergoing outpatient care at the Children's Health Polyclinic at Dr Saiful Anwar Malang. The sample of this study was taken by consecutive sampling from populations that met the inclusion as follows:1.) Children with a diagnosis of mild and moderate asthma based on the national asthma guidelines criteria, 2.) Patients aged 5-15 years, 3.) Parents of patients voluntarily allow their children to join the study after getting an explanation. And exclusion criteria: 1.) The subject who has immunodeficient, autoimmune diseases, chronic infections, and malignancies, 2.) Patients who are taking leukotriene antagonists, corticosteroids, theophylline, anticholinergics, chromolin and ketolifen in the two weeks before the study, 3.) Patients who are taking vitamin $\mathrm{D}$ in the past one month.

The subjects who met the inclusion and exclusion criteria were subsequently assessed to their clinical assessment, ACT (Asthma Control Test) scores, and blood sampling (vitamin D, Ig E and eosinophil levels). Vitamin D examination was carried out in

\section{Tabel 1. Baseline Characteristics of Respondents}

\begin{tabular}{lc}
\hline \multicolumn{1}{c}{ Characteristic } & Respondents (N=40) \\
\hline Gender, n (\%) & $28(70.0)$ \\
Male & $12(30.0)$ \\
Female & 7.6 \\
Age range (years) (mean), n (\%) & $21(52.5)$ \\
5-7 & $15(37.5)$ \\
$7-10$ & $4(10.0)$ \\
10-18 & \\
Vitamin D status, n (\%) & $6(15.0)$ \\
Deficiency (<20 ng/ml) & $18(45.0)$ \\
Insuficiency (20-30 ng/ml) & $16(40.0)$ \\
Sufficiency (>30 ng/ml) & $28.16(28.1)$ \\
25(OH)D, mean (median) & $679.78(479.1)$ \\
Imunoglobulin E, mean (median) & $5.99(5.3)$ \\
Eosinophil, mean (median) & $20.15(21.0)$ \\
ACT Score, mean (median) &
\end{tabular}

the hospital laboratory using the Enzyme-linked Immunosorbent Assays (ELISA) method.

Data analysis was performed with a mean different test. Later, to determine the relationship between numerical data variables, the Pearson correlation test is performed for normally distributed data or with the Spearman test for unnormal distributed data. Statistical tests were considered significant if the p-value $\leq 0.05$. All calculations are carried out with SPSS for Windows software.

\section{RESULTS}

In this study, was founded 40 participated subjects who met the inclusions and exclusions criteria. The study characteristics dominantly consisted of male than women with a ratio of 2.3: 1 and 7.6 years in age average. Furthermore, based on vitamin D status, 6/40 patients were deficiency, 18/40 patients were insufficiency, and 16/40 patients were deficiency (Table 1). The mean level of $25(\mathrm{OH})$ D was $28.16 \mathrm{ng} / \mathrm{ml}$, while the mean IgE level was 679.78 (median: 479.1), and a mean eosinophil level of 5.99\% (median: 5.3\%). Finally, the mean ACT score evaluation was 20.15 (Table 1 ).

The mean levels of immunoglobulin E deficiency, insufficiency and sufficiency consecutively were 1730.35; 561.99; and 418.32 IU / ml. Statistically, the levels of immunoglobulin $\mathrm{E}$ in each group of vitamin $\mathrm{D}$ status have a significant difference $(\mathrm{p}$ $=0.002$ ) (Table 2). Based on the correlation test obtained a significant negative relationship between levels $25(\mathrm{OH})$ D with immunoglobulin $\mathrm{E}(\mathrm{p}=$ $0.002, r=-0.476$ ) (Figure 1).

The mean number of eosinophils based on vitamin D status was $3.83 \%$ in the deficiency group, $6.6 \%$ in the insufficiency group and $9.95 \%$ in the deficiency group by showing significant differences between groups $(\mathrm{p}=0.008)$ (Table 2). In the correlation test found a significant negative relationship between $25(\mathrm{OH}) \quad \mathrm{D}$ levels and eosinophil levels with moderate closeness $(\mathrm{p}=$ 0.002 and $r=-0.479$ ) (Figure 1).

The average ACT score in each group of vitamin D status did not show a significant difference ( $p$ $=0.320$ ) (Table 2). Based on the correlation test between $25(\mathrm{OH})$ D levels and ACT scores, no significant relationship was found between the two with values $(\mathrm{p}=0.195$ and $\mathrm{r}=0.209)$ (Figure 1$)$.

\section{DISCUSSION}

Based on gender distribution, the ratio of men to women was 2.3: 1, with an average age of 7.6-yearold. It is in line with a study conducted by Elnady et al., who found that the male ratio was 2:1 compared 
to female. ${ }^{13}$ Oppositely, Hanan et al. found that female asthma patients were more than male. ${ }^{14}$ These differences might be caused by the different of study design on each study.

Later, $40 \%$ subjects had serum vitamin D levels more than $30 \mathrm{ng} / \mathrm{mL}$ (sufficiency), $45 \%$ had $20-30$

Tabel 2. The Association of IgE, eosinophil, and ACT score compared to Vitamin D status

\begin{tabular}{lcccc}
\hline $\begin{array}{c}\text { Vitamin D } \\
\text { Status }\end{array}$ & (n=40) & Mean & SD & P-Value \\
\hline IgE & & & & \\
Deficiency & $6 / 40$ & $1,730.35$ & 570.38 & 0.002 \\
Insuficiency & $18 / 40$ & 561.99 & 478.97 & \\
$\quad$ Suficiency & $16 / 40$ & 418.32 & 451.10 & \\
Eosinophil & & & & \\
Deficiency & $6 / 40$ & 9.95 & 7.780 & 0.008 \\
Insuficiency & $18 / 40$ & 6.60 & 3.427 & \\
Suficiency & $16 / 40$ & 3.83 & 2.365 & \\
ACT Score & & & & \\
Deficiency & $6 / 40$ & 19.83 & 1.169 & 0.320 \\
Insuficiency & $18 / 40$ & 19.78 & 1.987 & \\
Suficiency & $16 / 40$ & 20.69 & 1.778 & \\
\hline
\end{tabular}

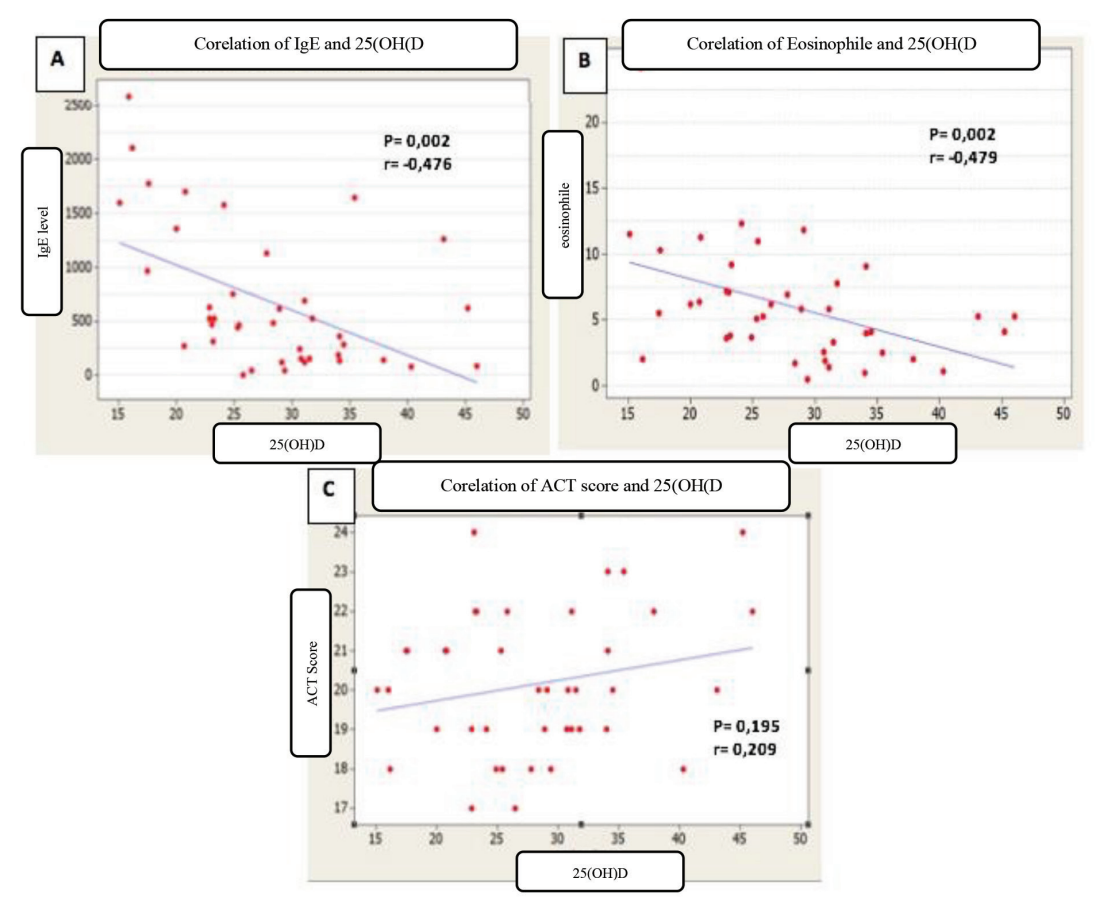

Figure 1. Correlation of 25(OH)D serum with imunoglobulin E, Eosinofil, and ACT Score in subjects

(A) a significant negative correlation between $25(\mathrm{OH})$ D levels and $\mathrm{IgE}$ levels with $\mathrm{p}=0.002$ and $\mathrm{r}=-0.476$; (B) a significant negative correlation between the level of $25(\mathrm{OH}) \mathrm{D}$ with the number of eosinophils $\mathrm{p}=0.002$ and $\mathrm{r}=-479$; $(\mathrm{C})$ no significant positive correlation between $25(\mathrm{OH}) \mathrm{D}$ levels and ACT scores with $\mathrm{p}=0.195$ and $\mathrm{r}=0.209$ $\mathrm{ng} / \mathrm{mL}$ (insufficiency), and the others $15 \%$ had less than $20 \mathrm{ng} / \mathrm{mL}$ (deficiency), while the average level of $25(\mathrm{OH}) \mathrm{D}$ in the whole sample was $28,162 \mathrm{ng} /$ $\mathrm{mL}$. Contrary to study which conducted by Souto Filho et al. found that the highest $25(\mathrm{OH}) \mathrm{D}$ status was in the sufficiency group with $53.5 \%$ subjects, followed by insufficiency (35.6\%) and (9.3\%) with deficiency status. ${ }^{15}$ This study is also contrasted to other studies in Turkey by Turkeli et al. who said that when asthma patients were divided into groups according to vitamin $\mathrm{D}$ levels founded a deficiency in $46.1 \%$ subject, $30.4 \%$ insufficiency, and $243.5 \%$ sufficiency. ${ }^{16}$

The difference in vitamin $\mathrm{D}$ status results from some of these studies may be influenced by several factors, including the fact that subjects with asthma spend time indoors frequently than other so that they may be exposed to less sunlight. The differences in geographical location can also affect exposure to sunlight, status nutrition, and vitamin $\mathrm{D}$ intake. Epidemiological study data show that the main factors that determine serum $25(\mathrm{OH}) \mathrm{D}$ levels are skin pigmentation (darker skin has $25(\mathrm{OH}) \mathrm{D}$ lower than those with lighter skin), sun exposure, age, sex, latitude shelter (higher latitude decreases the chance for vitamin D synthesis in the skin), diet, and vitamin D fortification. Several studies have proven this, despite having received fortified food and multivitamin intake, vitamin D deficiency still occurs in many countries thriving, even in areas with sufficient sun exposure. This prevalence is caused by changes in lifestyle, including a reduction in sun exposure, a shift from outdoor activities to indoor activities, the use of sunscreen, and dietary changes. ${ }^{17}$

The mean number of eosinophils from the entire subject was $5.99 \%$, with a median of $5.3 \%$. The details of the average number of eosinophils in each stratification of vitamin D status were $3.83 \%$ in the sufficiency group, $6.6 \%$ in the insufficiency group, and $9.95 \%$ in the deficiency group. The eosinophil levels in each vitamin $\mathrm{D}$ status group has a significant difference with $\mathrm{p}$-value $=0.008(\mathrm{p}<0.005)$. A study by Souto Filho et al. found that an average/median number of eosinophils in the vitamin D deficiency, insufficiency, and sufficiency group in the sequence were 245/238 cells / IL, 191/159 cells/lL, and 182 / 146 cells/lL with significant differences between each group. ${ }^{15}$

A negative correlation has found between $25(\mathrm{OH})$ D levels and blood eosinophil levels. These results are in line with the study of Brehm et al., which states that low serum vitamin D levels are associated with an increased number of eosinophils. ${ }^{18}$ Otherwise, Turkeli et al. ${ }^{16}$ and Alyasin et al. ${ }^{19}$ stated that the number of eosinophils in 
asthma patients was not significantly related to vitamin D status.

Three cytokines (IL-3, IL-5 and granulocytemacrophage colony-stimulating-factor (GM-CSF)) play a role in regulating and developing eosinophil in the bone marrow. Once in the tissue, the eosinophil releases Leukotriene (LTC) mediators, Platelet-activating-factor (PAF), reactive oxygen species, Major basic protein (MBP), ECP Eosinophil cationic protein, and Eosinophil derived neurotoxin $(\mathrm{EDN})$ resulting airway epithelial damage. ${ }^{5}$

Vitamin D has an immuno-modulator effect by acting on VDR expressed on B cells, T cells, dendritic cells, and macrophages. Vitamin D can inhibit both Th1 and Th2 type responses; hence the vitamin D can balance the immune response. Vitamin D also inhibits the production of eosinophils by blockade the response of Th2 type cells and resulting in the depression of IL-3 and IL-5. Also, vitamin D reduces cytolytic peroxidase release and reduces $\mathrm{IgE}$ production and increases anti-inflammatory cytokines. ${ }^{8,20}$

Based on the results of the correlation test, we found a significant negative relationship between vitamin $\mathrm{D}$ levels and immunoglobulin $\mathrm{E}$ and a moderate level of closeness of the relationship ( $\mathrm{r}$ $=-0.476, \mathrm{p}=0.002)$. This result was in line with a cohort study in Costa Rica involving 616 children with asthma, and the study states that an inverse relationship found between vitamin D levels and serum IgE.17-20 In contrast, Kang et al. found that $25(\mathrm{OH}) \mathrm{D}$ levels have no relationship with total serum IgE levels in asthma and allergic patients. ${ }^{22}$

Different study populations may cause conflicting results from several studies regarding the relationship between vitamin $\mathrm{D}$ and allergies or asthma. According to previous research, ethnicity and genetic polymorphism of individuals can also be an explanation for these conflicting results. Furthermore, Vimaleswaran et al. ${ }^{23}$ showed that vitamin D deficiency increased IgE levels only in subjects with the 'C' allele of interleukin-4 SNP rs 2243250 found in $86 \%$ of European whites, $26 \%$ Chinese, and $<20 \%$ of Africans.

Based on the correlation test shows that ACT Score and Vitamin $\mathrm{D}$ have a positive but not statistically significant $(p=0.195, r=0.209)$. In line with research which was conducted by Pollard et al. $^{24}$ who found no significance between 25 $(\mathrm{OH}) \mathrm{D}$ levels with ACT scores and improvement in lung function. The results of a recent metaanalysis from Cochrane showed that vitamin D supplementation significantly reduced the risk of asthma exacerbations requiring oral corticosteroids (ratio of $0.63,95 \%$ CI: $0.45-0.88$ ). The risk of hospitalization is also significantly reduced, despite evidence of moderate quality. In our study, there was a positive correlation between $25(\mathrm{OH}) \mathrm{D}$ levels and ACT scores, although not significantly. ${ }^{2}$ The difference may because of the many risk factors that influence the level of asthma control and recurrences of asthma, like triggers, gender, weather changes, type of food, lifestyle and atopic history.

The limitation of this study was the absence of genetic factors, lifestyle factors, and allergen factors which trigger asthma in the subject. Moreover, the cross-sectional design is unable to assess the temporality or causal relationship to each variable. For this reason, a well-designed randomized controlled trial of supplementation is needed to clarify the relationship between vitamin D deficiency and asthma.

From the results of this study, it can be concluded that there is a significant negative relationship between serum $25(\mathrm{OH})$ D levels with total immunoglobulin $\mathrm{E}$ levels and the number of eosinophils in mild and moderate asthma children. However, serum $25(\mathrm{OH})$ D levels have a nonsignificant positive relationship with clinical asthma control test (ACT) scores.

\section{CONFLICT OF INTEREST}

The authors declare no conflict of interest regarding the publication of this article.

\section{ETHIC}

This research has been conducted an ethics test and was declared ethical by the RSU research ethics team. Dr. Saiful Anwar Malang.

\section{AUTHOR CONTRIBUTION}

All authors have contributed to all process in this research, including preparation, data gathering and analysis, drafting and approval for publication of this manuscript.

\section{FUNDING}

The authors are responsible for all of the study funding without the involvement of grant or any external source of funding.

\section{REFFERENCE}

1. Global Initiative for Asthma (GINA). 2016. Global strategy for asthma management and prevention. GINA committees:134-135.

2. Martineau, Cates, Urashima, Jensen, Griffiths. 2016. Vitamin D for the management of asthma. Cochrane Database of Systematic Reviews; 9.

3. Badan Penelitian dan Pengembangan Kesehatan Kementrian Kesehatan RI, 2013, Riset kesehatan dasar tahun 2013. 
4. Ali \& Nanji. 2017. Review on the role of vitamin D in asthma. Cureus. 9 (1288): 1-12.

5. Mc Brien \& Menzies. 2017. The Biology of Eosinophils and Their Role in Asthma. Front Med. 4:93

6. Bantz \& Zhu,Zheng. 2015. Role of vitamin D in pediatric asthma. Ann Pediatr Child Health. 3:1-8.

7. Szodoray,, Nakken, Gaal, Jonsson, Szegedi. The complex role of vitamin D in autoimmune disease. Scandinav Jour Immunol. 68:261-269.

8. Subandiyah, K., Khanifa, H., Kardani, A.K. 2018. Effect of corticosteroid and vitamin D3 as combined therapy on 25 $(\mathrm{OH})$ vitamin D serum level and regulatory T (TReg) cells population in children with idiopathic nephrotic syndrome. Bali Medical Journal 7(3): 639-644. DOI:10.15562/bmj. v7i3.769

9. Devereux, Wilson, Avenell. 2014. A case-control study of vitamin D status and asthma in adults. Allergy. 65:666-667.

10. Thuesen, Skaaby, Husemoen. 2015. The association of serum $25-\mathrm{OH}$ vitamin $\mathrm{D}$ with atopy, asthma, and lung function in a prospective study of Danish adults. Clin Exp Allergy.45:265-272.

11. Montero, Meija, Ramos. 2013. Vitamin D insuffiency and asthma severity in adults from Costa Rica. Allergy Asthma Immunol Res. 5(5):283-288.

12. Hypponen, Berry, Wejst, Power. 2009. Serum 25-hydroxyvitamin D and lgE-a significant but nonlinear relationship. J Allerg, 64(4):113-120.

13. Elnady, Fouda, Elsheikh, Alameey, Shafie. 2013. Serum vitamin D level as a predictor of bronchial asthma in Egyptian children. J Arab Soc Med Res. 8:67-73.

14. Hanan, Gamal, Nabil, Nevine, Eman. 2016. Assessment of Vitamin D and Iron Levels in Childhood Asthma. IJPCR. 8(10): 1407-1413.

15. Souto Filho, Andrade, Mesquita Ribeiro, Sardenberg, Simonini. 2017. Impact of vitamin D deficiency on increased blood eosinophil counts. Hematol Oncol Stem Cell Ther. 11:25- 29.

16. Turkeli, Ayaz, Uncu, Ozhan, Bas, Tufan. 2016. Effects of vitamin $\mathrm{D}$ levels on asthma control and severity in preschool children. Eur Rev Med Pharmacol Sci. 20:26-36.
17. Hall \& Agrawal. 2017. Vitamin D and Bronchial Asthma : An Overview of Data From the Past 5 Years. Clin Ther. 39(5):917-929.

18. Brehm, Celedon, Soto-Quiro, Avila, Hunninghak, Forno et al. 2009. Serum vitamin D levels and markers of severity of childhood asthma in Costa Rica. Am J Respir Crit Care Med. 179:765-71.

19. Alyasin, Momen, Kashef, Alipour, Amin. 2011. The relationship between serum 25 hydroxy vitamin D levels and asthma in children. Allergy Asthma Immunol Res. 3:251-255.

20. Girolamo, Alessandro, Busceti, Gallelli, Cecilia, Rosa et al., 2015, Cellular mechanisms underlying eosinophilic and neutrophilic airway inflammation in asthma. J. Med Inflam. 201:1-7.

21. Gupta, Sjoukes, Richards, Banya, Hawrylowicz. 2011. Relationship between Serum Vitamin D, Disease Severity,and Airway Remodeling in Children with Asthma. Am J Respir Crit Care Med. 184:1342-1349.

22. Kang, Hong Kim, Jik Kim, Gweon Lee, Heon Yoon,Hoon Kim. 2015. Association of serum 25-hydroxyvitamin D with serum IgE levels in Korean adults. J. Auris Nasus Larynx.06(10):1-5.

23. Vimaleswaran, Cavadino, Hypponen. 2012. Evidence for a genetic interaction in allergy-related responsiveness to vitamin D deficiency. J. Allergy.67:1033-1040.

24. Pollard, John, Lima, Romero, Tarazona-Meza, Mougey. 2017. Associations between serum 25(OH)D concentrations and prevalent asthma among children living in communities with differing levels of urbanization: a cross-sectional study. Asthma Research and Practice 3 (5):1-11.

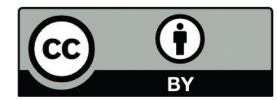

This work is licensed under a Creative Commons Attribution 